\title{
Earthquake Disaster Risk Reduction in Iran: Lessons and "Lessons Learned" from Three Large Earthquake Disasters-Tabas 1978, Rudbar 1990, and Bam 2003
}

\author{
Michaela Ibrion ${ }^{1} \cdot$ Mohammad Mokhtari $^{2} \cdot$ Farrokh Nadim $^{3}$
}

Published online: 18 December 2015

(c) The Author(s) 2015. This article is published with open access at Springerlink.com

\begin{abstract}
This article addresses three large earthquake disasters in Iran: Tabas in 1978, Rudbar in 1990, and Bam in 2003. Lessons and "Lessons Learned" from these three earthquake disasters were investigated together with their contributions over time towards earthquake disaster risk reduction in Iran. Many lessons from 1978 Tabas, 1990 Rudbar, and 2003 Bam did not become "Lessons Learned" and they were identified again within the dramatic context of other earthquake disasters in various places of Iran. Both lessons and "Lessons Learned" from Tabas, Rudbar, Bam, and other earthquake disasters in Iran require a sustainable long-term framework-an earthquake culture.
\end{abstract}

Keywords Bam - Earthquake disaster risk reduction · Lessons · Lessons learned - Rudbar · Tabas

\section{Introduction}

We live on seismically active planet (Bilham 2009) and in a "world risk society" (Beck 2008, p. 1) in which it is neither realistic nor practical to eliminate risk (Lacasse et al. 2004). Risk is ubiquitous in our global world (Jaeger

Michaela Ibrion

Michaela.Ibrion@svt.ntnu.no; mibrion5@gmail.com

1 Department of Geography, Faculty of Social Sciences and Technology Management, Norwegian University of Science and Technology (NTNU), 7490 Trondheim, Norway

2 National Center for Earthquake Prediction and Seismological Research, International Institute of Earthquake Engineering and Seismology (IIEES), Tehran, Iran

3 Natural Hazards, Debris Slides and GeoRisk, Norwegian Geotechnical Institute (NGI), 0806 Oslo, Norway
2010) and earthquake risk can never be eliminated, but it can be reduced to an acceptable or tolerable level (Lacasse et al. 2012). Society has the potential to influence earthquake consequences and the severity of earthquake disasters. Communities and societies need to learn to live and to cope with earthquake hazard. Earthquake disaster preparedness needs to shift from reaction to pro-action. The focus should not only be on emergency relief and recovery, but also on the mitigation of earthquake disaster risk, building resilience, learning from experiences and past mistakes, and constant implementation of disaster risk reduction measures (Bilham 2009; Lacasse and Nadim 2011; Alexander 2012a).

In disaster risk reduction arena and specifically earthquake risk reduction, lessons and especially "Lessons Learned" became an important matter in the last decades (Alexander 2012a, b). The key question is whether the identified lessons from earthquake disasters can be considered as "Lessons Learned" and have adequately improved earthquake disaster risk reduction. To answer this question, Iran was selected as a study area. Iran is situated in a high seismic part of the Alpine-Himalayan belt and has a long history of frequent earthquake disasters that have caused large numbers of deaths, injuries, and massive destructions (Ambraseys and Melville 1982; Berberian et al. 1992; Berberian 2014). Earthquakes in Iran have often resulted in disasters (Berberian 2014; Ibrion et al. 2015a). Three earthquake disasters that were considered among the worst and deadliest disasters in Iran in the last 100 years were examined in this study: Tabas in 1978, Rudbar in 1990, and Bam in 2003. Within the studies of earthquake disasters, narratives of disasters and survivors have an important contribution (Simpson and Corbridge 2006; Ibrion et al. 2015b). For this study, the narratives of earthquake survivors were collected through in-depth 
interviews conducted in Rudbar in 2012 and Bam in 2010 and 2012. Archival documents were consulted for the Tabas area. Other ethnographic methods were also employed, such as personal observations, photos, home visits, visits to and interviews at public places, mosques, and shrines. Secondary sources-various academic and scientific materials, earthquake field reports, and cartographic materials-were also used.

\section{Lessons and "Lessons Learned"}

What does the concept of lessons and "Lessons Learned" mean in the arena of disaster risk reduction? The terminology related to risk and disaster risk reduction is confronted with what Thywissen (2006) called "Babylonian confusion," which means that different meanings are connected with different people and different contexts. Lessons from earthquake disasters relate to the knowledge acquired through earthquake experiences, overlooked matters, key issues, important measures, challenges, unsolved problems during the time, urgent requirements for essential changes, adaptations, implementations, various strategies of earthquake disaster mitigation, and preparedness (Atsumi and Okano 2004; Ibrion et al. 2015c). Lessons from earthquake disasters need to be applied and "learned" at different scales, starting from individuals and families to local communities and the regional, national, and international levels (Ibrion et al. 2015c). "Lessons Learned" are considered as essential references for earthquake disasters preparedness (Zhang et al. 2012) and contributes to a culture of resilience and earthquake disaster risk reduction (Ibrion et al. 2015c), as their purpose is to mitigate "short cuts to disasters" (Ozerdem and Barakat 2000, p. 425). Krausmann and Mushtaq (2006) argued that "Lessons Learned" are an essential part of risk reduction and one reason why disasters still occur is because the lessons of past events have not been learned or have not been implemented yet in risk management practices. In terms of lessons and "Lessons Learned," Glantz and Kelman (2013) refer to an old saying "Once bitten, twice shy," that is people remember dramatic experiences and try to avoid them in the future. Moreover, Glantz and Kelman (2013) emphasized that "Lessons Learned" are those lessons that have better consequences for disaster reduction, provided they are implemented. A lesson becomes a "Lesson Learned" when that lesson contributes to the mitigation process (Alexander 2012b), the improvement of safety and security (Alexander 2012a), and the reduction of death toll from earthquake disasters, to enhance the resilience of communities and improve earthquake disaster preparedness (Ibrion et al. 2015c). Leroy et al. (2010) emphasized the importance of knowing, understanding, communicating, and learning the lessons from past disasters. Kasperson (2010) underlined also that together with risk analysis, social learning has impact on the dimensions of disasters.

\section{Lessons and "Lessons Learned" from the Tabas 1978 Earthquake Disaster}

The Tabas earthquake occurred on Saturday, 16 September 1978, at 19:38 local time when most of the local people were at home. Tabas oasis is situated between two deserts in Iran: the Dasht-e Kavir (Great Desert) and the Kavir-e Lut (Lut Desert). The Tabas earthquake was a large-magnitude earthquake of $\mathrm{M}_{\mathrm{w}}$ (moment magnitude) 7.4 (Berberian 2014). It had the highest magnitude among the 231 seismic events that occurred in this part of Iran from 1900 to 2014 .

The Tabas earthquake occurred almost one year after the Dasht-e Bayaz earthquake and was caused by an "unmapped" and "unkown" fault, situated in the western part of the Shotori Mountains. It seems that prior to this earthquake, in the Tabas area a "seismic quiescence" of at least 1000 years had occurred in terms of large-magnitude earthquakes (Berberian 2014). The population of Tabas was terribly affected. About $85 \%$ of Tabas inhabitants were killed, amounting to 11,000 from a total population of 13,000. The total number of people killed by the earthquake reached 20,000, as 90 villages around Tabas were destroyed or severely damaged, and 50 additional villages suffered slight damages (Berberian 2014). The direct economic losses were estimated at USD 11 million (Berberian 2005). Different architectonic monuments and cultural heritage of Tabas, including various parts of Arg-e Tabas (Citadel of Tabas) were totally destroyed by the earthquake (Berberian 2014). Moreover, the symbol of Tabas-Bagh-e Golshan (The Golshan Garden) was totally destroyed and its famous white pelican known as "Pelican of the Desert" died (Ettelaat Archives 1978). The unfortunate occurrence of a total lunar eclipse $2 \mathrm{~h}$ after the main shock, together with the breakdown of the Tabas power station, severely affected the rescue operations performed by the survivors (Ambraseys and Melville 1982; Berberian 2014). The huge number of deaths affected the local rescue efforts and the organized search and rescue missions were in delay after the Tabas earthquake (Berberian 1979; Parsizadeh 2011). High number of deaths, high temperatures, pestilential smells, fears of diseases, and beliefs about immediate burial of dead bodies were among the factors that influenced the handling of dead people after the Tabas earthquake. Dead people were buried immediately and in many cases, proper identification and respect of the funerary rituals were not done. This situation negatively affected 
adaptive and coping capacities of survivors (Ibrion et al. 2015b). The lesson of handling of dead bodies was identified also after the Rudbar 1990 and Bam 2003 earthquake disasters (Ibrion et al. 2015a, b). After the Rudbar earthquake, landslides completely buried some villages so no bodies could be found. In Fatalak village near Rudbar, family members who were away from the village at the fatal time of the earthquake and the landslides performed funerary ceremonies in the absence of the bodies of their missing family members, at places that were thought to be the sites of their houses (Shahrivar and Nadim 2005). After the Bam 2003 earthquake, the handling of dead bodies was even more dramatic than for other previous earthquake disasters. Many people were buried without proper identification and funerary rituals were not respected. According to the narratives of survivors, there were even cases that people were almost buried alive, and even the possibility that some of them were buried alive (Ibrion et al. 2015b). Many people did not know for a long time whether their family members and relatives were dead or alive, or if dead, where they were buried. These devastating aspects of the disaster undermined resilience of the survivors (Ibrion et al. 2015b). The handling of the dead people according to cultural tradition and the funerary rites and rituals was implemented after the 2013 Shonbeh-Bushehr earthquake in the southwestern part of Iran. All dead people were properly identified and buried on the third day after the earthquake. The funerary ceremonies were conducted according to the cultural traditions and attended by families, relatives, community members, and officials (IIEES 2013). The 2013 Shonbeh-Bushehr earthquake death toll is hardly comparable with those from Tabas and Bam, but it is worth to mention that the proper handling of dead people had a positive impact on the adaptive and coping capacities of affected communities (IIEES 2013; Ibrion et al. 2015b).

Safety and security is another essential issue for earthquake survivors. After the Tabas earthquake, rescue forces, relief organizations, and volunteers adhered to strict safety measures implemented by the national army forces to ensure safety of survivors and to prevent looting. Some incidents, however, did occur (Ibrion et al. 2015b). Survivors' safety was a major concern under the tragic situation after the Bam earthquake. Looting referred as "a disaster myth" or a "misconception about disasters" (Lopez-Carresi 2014) became a dramatic reality in Bam. After the Bam earthquake, a dramatic breach of the safety of survivors occurred and "looting time" unfolded (Ibrion et al. 2015b). Many accounts of survivors emphasized the high insecurity in Bam from the first hours until 2-3 days after the earthquake when national army reached the area: "... in the first hours of the earthquake, whatever thieves were in Iran, came to Golbaf [a town near Bam] and came between people [in Bam]" (Parsizadeh 2011, p. 116). Even relief items like tents and blankets delivered by Red Crescent of Iran were subject to armed robbery (Parsizadeh 2011). Looting affected the survivors, rescue and relief organizations, and even impacted dead bodies. One of Bam's survivors recounted very disturbing scenes: "They were stealing the stuff of people and putting in the car and adding one or two more dead bodies on top of the car or on the taken stuff. When passing through the security checks, out of the city, they were saying these are our families and we are taking them to be buried out of the city. However, after passing the security check points, they were just throwing away the dead bodies" (Ibrion et al. 2015b, p. 71). The lesson of assuring safety and security of survivors was later learned and implemented after other earthquake disasters in Iran. This was the case, after the 2013 Shonbeh-Bushehr earthquake, when special police forces, together with the army, were deployed within the first hours after the earthquake. Survivors, their belongings, private and official buildings, roads, and the distribution of relief items were subject to a vigilant and tight safety and security control. Only a single incident of burglary occurred-a person stole a TV, but was immediately caught and confined (IIEES 2013).

Tabas is situated in an arid area where the main source of water is represented by the underground water resources. At the time of earthquake, the water was tapped through underground tunnels named Qanats. Qanats represent the Persian traditional water system, are centuries old and still in use in Iran. After the Tabas earthquake, the Qanat system was seriously affected and providing water for survivors was very challenging. It is not clear how long it took for the Qanats of Tabas area to be repaired, but weeks and even months after the earthquake, the water was brought in from places situated hundreds of kilometers away. This had a negative effect on the resilience of survivors (Ibrion et al. 2015b). This problem was encountered again after other earthquakes in the arid areas, for instance, the 2003 Bam earthquake (Ibrion et al. 2014, 2015b). After the Bam earthquake, the most serious "geotechnical effect" was the collapse of qanats bringing water from the aquifers of mountains to Bam, Baravat, and villages around them (ICG 2004, p. 3; Nadim et al. 2004). The agriculture of Bam and Baravat, especially the famous date and citrus orchards are dependent on the water transported through the Qanats. At the time of the earthquake, 1,600,000 date trees existed in Bam and vicinity area. Bam dates are famous through their sales in Iran and export around the world and are considered important sources of income for the local people (Nadim et al. 2004). Repair of Qanats started immediately after the earthquake. However, the existence and function of Qanats in arid and semi-arid areas of Iran is constrained and menaced by unsustainable policies and actions, massive usage of wells and pumps, construction of dams, and 
especially the depletion of underground water reserves (Ibrion et al. 2014).

\section{Lessons and "Lessons Learned" from the Rudbar 1990 Earthquake Disaster}

The Rudbar earthquake occurred on Thursday, 21 June 1990 , half an hour after midnight local time, with a $\mathrm{M}_{\mathrm{w}}$ of 7.3 (IIEES 1990; Berberian et al. 1992). It was one of the largest instrumentally recorded events in the Western Alborz Mountains in northern Iran, southwest of the Caspian Sea (Berberian et al. 1992). The Rudbar earthquake had the highest magnitude among the 377 seismic events that occurred in this part of Iran from 1900 to 2014.

It was one of the deadliest and most destructive earthquakes in Iran as more than 40,000 people were killed, 60,000 people were injured, and more than 500,000 people were left homeless. The Rudbar earthquake destroyed three cities, Rudbar, Manjil, and Lowshan, and 700 villages and slightly damaged another 300 villages in the Gilan and Zanjan Provinces. Almost 100,000 buildings were destroyed or badly damaged and farms and irrigation channels suffered serious damages (Berberian and Walker 2010; Berberian 2014). The total cost of reconstructing only the villages in the Zanjan and Gilan Provinces was estimated to be 200 billion Rials, approximately USD 2.8 billion at that time (Berberian et al. 1992).

Given the high death toll and a high number of injured and homeless people, psychological support for the survivors became an urgent need. Recognizing and supporting the psychological needs of survivors was a lesson from this earthquake. Measures were step by step implemented and a national program with the goal of delivering mental health services to the survivors of earthquake disasters was slowly, but steady developed. A special subcommittee for health and medical care, under the umbrella of the Ministry of Health and as part of the National Committee for Disaster Reduction in Iran (NCDRI) was established and endorsed the action plans. A special program for supporting the psychological needs of disasters survivors was gradually developed. Training and workshops were offered to the Red Crescent and other organizations involved in earthquake disaster rescue and relief operations (Yasamy et al. 2006). After the Shiran-Ardebil and Zirkuh-Qa'enat earthquake disasters in 1997, two mental health needs assessments of the survivors were carried out and psychological interventions recommended. Furthermore, the 2002 Changureh-Avaj earthquake in the Qazvin area and the 2003 Bam earthquake demanded further actions in the trauma counselling and mental health support of survivors (Yasamy et al. 2006). After the Bam earthquake disaster, the tragic reality was that almost all of the families in Bam were affected by deaths, injuries, and destruction. Bam disaster highlighted the need for psychological support at various stages of disaster and importance of preparing and deploying a comprehensive psychosocial intervention program in case of large earthquake disasters. But the logistics and financing of such a program need to be carefully planned (Yasamy et al. 2006). Another identified lesson after the Bam earthquake was that the psychological needs and trauma care of the survivors are best attended to by local health staff, people who share the same language and culture with survivors (De Ville de Goyet 2007). However, mental problems are not easily discussed and mental health issues have an unbearable stigma among people. Cultural traditions and beliefs in Iran are positively perceived of alleviating the immense trauma caused by earthquake disasters. As per a survivor of four earthquake disasters, including Tabas and Bam, it is vital during disasters to give deldary (peace in the heart) to survivors. In practical terms, deldary requires the expression of empathy for the survivors' losses, the conveyance of condolences, but also an effort to empower the survivors, to help them to believe that there is still hope in their lives and they need to act accordingly. Deldary had a good effect on the mental health of people and on their coping capacity (Ibrion et al. 2015b). A woman survivor of the Bam earthquake recounted that for years after the earthquake she went to yoga classes and travelled to Mashad-a pilgrimage' city - to pray for the lost family and relatives. A survivor of the Rudbar earthquake recalled also that "Everybody died in the family... that night I was not there. I always think of them. Two of my cousins also survived. We went together to pray for our families to the Holy Shrine of Imam Reza in Mashad. Almost every week we go to pray to Imam Zadeh [a pilgrimage place]" (Fig. 1).

Another major problem after the Rudbar earthquake was the massive damage caused by liquefaction and earthquake-induced landslides to the villages, roads, farms, and landscape of the area. An extensive loss of life was also added. A survivor of Rudbar earthquake recounted that "We were lucky to escape alive. We were watching the football cup match that time. I was just thrown out through the window. I saw the neighbor house going down the valley. I had a garden with olives, but all was lost because of landslides." Around 100 landslides occurred, and two landslides of Rudbar and Fatalak were very destructive. Whole villages disappeared as a result of such severe landslides (Shahrivar and Nadim 2005). Liquefaction also caused great damages to the area (Astaneh and GhaforyAshtiany 1990; IIEES 1990). This situation required adequate mitigation measures for the Rudbar area and for other mountainous parts prone to landslides and liquefaction. Starting from 1991, landslides and liquefaction studies became part of the Iranian national earthquake mitigation 


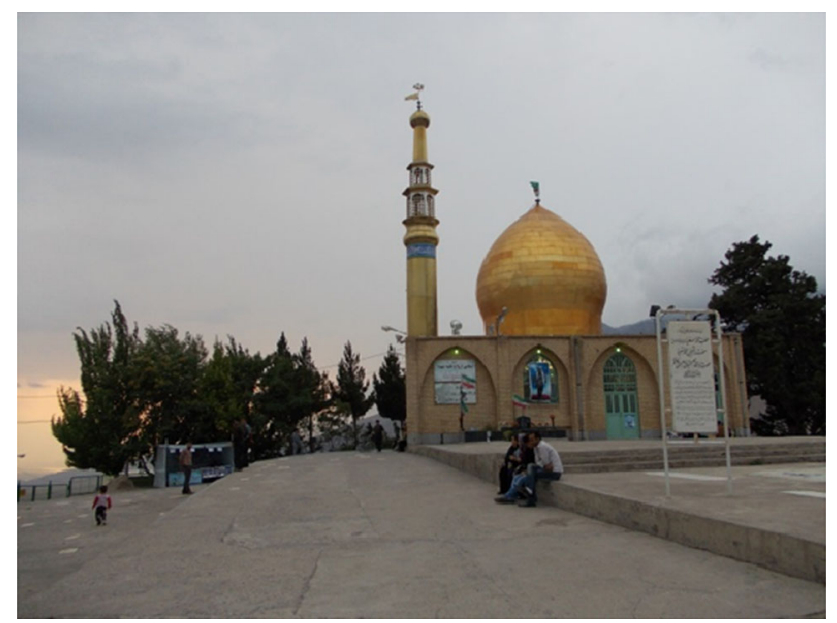

Fig. 1 Shrine of an Imam Zadeh-a pilgrimage place-near the Rudbar-Manjil area. Photograph by M. Ibrion, 2012

plans. Geological and geotechnical investigations of the zones at risk started to be conducted in the decades following the Rudbar earthquake (Ghafory-Ashtiany et al. 2000). But careful planning, adequate finance, and implementation of mitigation measures for landslides and liquefaction require continuous efforts and integration within the disaster preparedness in Iran.

Landslides and rock falls affected the roads for several months after the earthquake. The highway between the cities of Qazvin and Rasht that passes through the cities of Lowshan, Manjil, and Rudbar was blocked by such huge rocks that repeated detonations were required to clear the highway (IIEES 1990). Many other mountain roads were also blocked for a long time and impeded access to the affected areas (Fig. 2). Consequently, rescue, relief, and reconstruction efforts were considerably delayed. After the

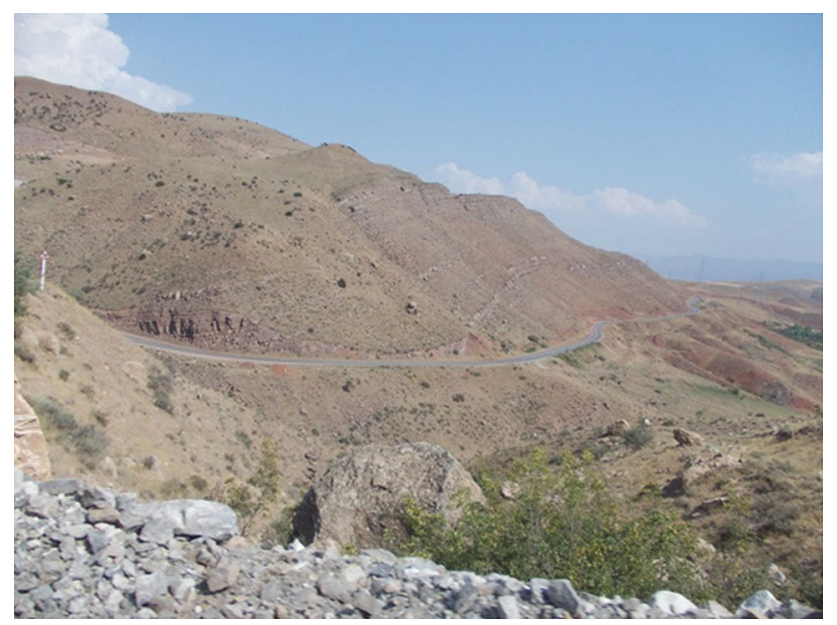

Fig. 2 A narrow mountain road to the village of Jirandeh (ManjilRudbar area). Photograph by M. Ibrion, 2012 earthquake, more than $1200 \mathrm{~km}$ of rural road needed repair or reconstruction (Berberian et al. 1992).

Another lesson concerned the public education and measures that help to reduce the traffic load on roads and highway in case of earthquake. After the Rudbar earthquake, a huge traffic load occurred on the roads passing through the affected earthquake areas. This situation was similar to the 1995 Kobe earthquake in Japan. Blockage of roads after the earthquake indicated the need for better disaster preparedness to prevent delays in the delivery of rescue and relief to survivors. This lesson was implemented in disaster management and became "Lesson Learned" in Iran after the Bam earthquake and in Japan, after the 2004 Niigate earthquake and the 2011 Great East Japan Earthquake (Ranghieri and Ishiwatari 2014).

A lesson that concerned the improvement of the seismic performance of buildings also emerged after the Rudbar earthquake disaster. Masonry and stone buildings suffered extensive damage and destruction and the performance of adobe buildings during the Rudbar earthquake was very poor. Private buildings and essential buildings such as hospitals, municipal offices, fire stations, police quarters, telecommunication buildings, factories, silos, and water tanks either collapsed or suffered major structural and nonstructural damages. The two-storey Rudbar Hospital, built in 1987 at a cost of 600 million Rials (approximately USD 500,000), and the Rostamabad Hospital with modern facilities completed just two years before the earthquake, were both destroyed, along with another 85 healthcare centers and hospitals. In addition, hundreds of hospitals and health units suffered damages (Astaneh-Asl 1994; Berberian and Walker 2010). Another lesson of the Rudbar earthquake was that structural and nonstructural elements of buildings, as well as the installations of equipment inside the essential buildings, all need to comply with the seismic codes requirements and to follow strict quality controls during construction (Astaneh-Asl 1994). However, the poor seismic performance of adobe buildings, stone and unreinforced masonry buildings was not new for Iran. This was identified and well known for many years before the Rudbar earthquake. Previous earthquakes like the Buyin Zahra earthquake in 1962 with 12,200 fatalities, the Dashte Bayaz earthquake in 1968 with 10,000 deaths, and the Tabas earthquake in 1978 with a death toll of 20,000 are just a few of earthquake disasters that draw attention to this lesson. Astaneh-Asl (1994, p. 6998) even called the adobe houses of Iran "death traps." The need to improve the poor seismic performance of buildings in Iran was first addressed with the adoption of buildings codes in Iran. After the Buyin-Zahra earthquake in 1968, an international seminar under the United Nations Educational, Scientific and Cultural Organization (UNESCO) patronage was organized at the University of Tehran. A preliminary report about the 
first Iranian buildings code was discussed at this seminar. Such code was prepared based on the United States Uniform Building Code and San Francisco, California code. Iranian Standard ISIRI (Institute of Standards and Industrial Research of Iran), code no. 519 was the first national Iranian code for the seismic resistance building design. It was approved and started to be implemented from 1969 (Berberian 2014). The second revised ISIRI code no. 2800 was approved in February 1988. For the first time, a map of Iran with its seismic zones based on the active faults was used for the preparation of this second ISIRI code (Berberian 2005, 2014). However, many buildings collapsed during the 1990 Rudbar earthquake and took a large number of lives. One of the main reasons was the noncompliance with the requirements of the seismic codes and the lack of codes enforcement. Other practical and economic reasons can be identified as well: many towns and villages are situated in remote areas and are not easily accessible; problems with the availability and delivery of construction materials; shortage of qualified people in the construction field; the need of costly equipment; the high number of buildings that need to be retrofitted; and lack of financial resources from community, local, and national budgets (Astaneh-Asl 1994). Reconstruction process after the Rudbar earthquake was highly impacted by the above mentioned factors (Fig. 3).

The lesson regarding the necessity of improving the seismic performance of buildings in Iran was identified again after the 2003 Bam earthquake disaster. Another issue identified after the Rudbar earthquake concerned the Manjil concrete dam built in 1967 on the Sefidrood River. The dam sustained only minor damages at its top and

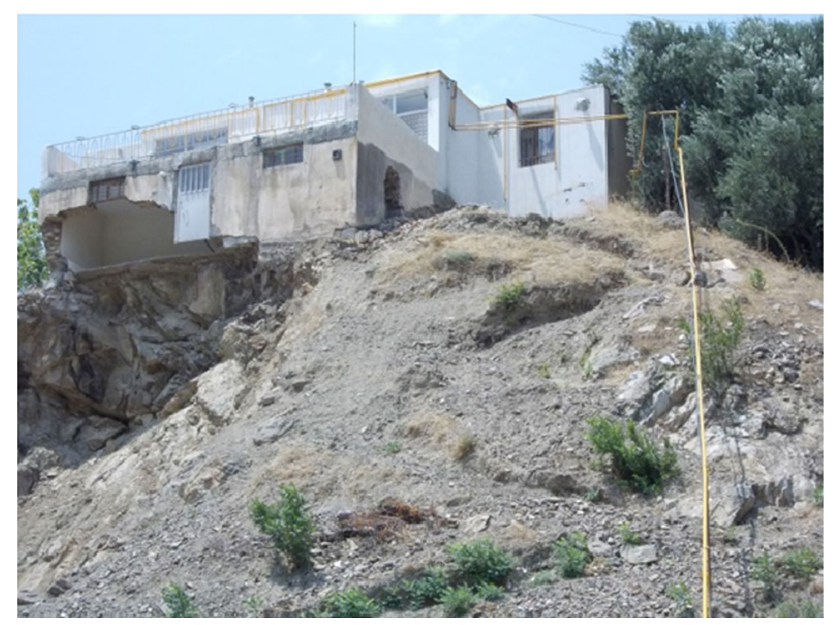

Fig. 3 A house in Rudbar. The front part of the house was still in ruins in 2012 and the back part of the house was reconstructed and built over many years after the 1990 Rudbar earthquake. Note the unsafe connection of the house to gas (yellow pipe at the right side of the photo). Photograph by M. Ibrion, 2012 buttresses. But the seismic performance of the Manjil dam drew attention to the possibility of disastrous consequences in case of dam failure and the necessity of continuous earthquake engineering monitoring (IIEES 1990; AstanehAsl 1994).

After the Rudbar earthquake, the oil and gas pipelines suffered damages for a distance of several kilometers. The need to improve the seismic performance of oil and gas pipelines and adjacent facilities suggested the improvement of gas facilities design and monitoring in other bigger and heavily populated cities such as Tehran, Tabriz, and Mashad (IIEES 1990). In addition, in Manjil town it took more than $30 \mathrm{~min}$ after the earthquake to shut down the gas flow. The failure of electric power supply and the strong wind of Manjil that dissipated the gas contributed to the fortunate situation that no explosions or fires occurred after the earthquake.

The time spent by people under the rubble is an essential factor that needs to be carefully considered by emergency teams or other rescuers, at local, regional, and national levels, as longer time dramatically increases the number of fatalities. The Rudbar earthquake occurred after midnight local time, which significantly contributed to the loss of life, as the night made it very difficult or even impossible for survivors to rescue the rest of their families, neighbors, or other people in the area (Berberian et al. 1992). Many people died not necessarily from injuries, but rather from asphyxiation and because they could not be extricated in time from under the debris. In addition, the search and rescues activities of Red Crescent Society of Iran were delayed by the wrong information received from the Geophysics Institute of Tehran and difficulties in identifying the epicenter area (the area that was most affected by the impact of earthquake). Under such conditions, the "golden time" that corresponds to the immediate hours after an earthquake was lost. The death toll increased and the coping capacity of survivors was affected. This lesson was repeated and did not become a "Lesson Learned" after many other earthquakes in Iran, including the Buyin Zahra 1962, Tabas 1978, and later on, Bam 2003 earthquakes (Ibrion et al. 2015a). People under the rubble were saved by family members, neighbors, or other members of their community. The important role of local communities within earthquake disaster management, in rescue, relief, and reconstruction was part of the lesson that started to become articulated after the Rudbar earthquake. The need to enhance the public earthquake awareness and education was also identified as a lesson from the Rudbar earthquake (Izadkhah and Hosseini 2010). The importance of this lesson was reinforced after other earthquake disasters such as the Changureh-Avaj 2002, Bam 2003, and Shonbeh-Bushehr 2013 earthquakes. 


\section{Lessons and "Lessons Learned" from the Bam 2003 Earthquake Disaster}

On Friday, 26 December 2003 at 05:26 local time, an earthquake of $M_{w} 6.6$ destroyed Bam city and affected the town of Baravat and nearby villages, in Kerman Province of southeast Iran, on the west side of Kavir-e Lut (Nadim et al. 2004; Berberian 2014). The Bam earthquake was a moderate magnitude seismic event among the 644 seismic events that occurred in this part of Iran from 1900 to 2014.

The Bam earthquake was a seismic event of moderate magnitude, but the Bam earthquake disaster was a sad example of the way how a moderate geological event can affect unprepared communities and society (Berberian 2005). Bam earthquake occurred on Friday - the official weekend holiday in Iran - and the majority of people were indoors, either still sleeping, or preparing for morning prayer. In the night of the earthquake it was unusually cold outside, with the temperature well under zero degrees. Cold weather, the cultural landscape of Bam, and the strong cultural beliefs hindered the evacuation of buildings, despite the warning foreshocks (Ibrion et al. 2014). The death toll was subject to controversies and various estimations offered a number between 26,500 and 43,000 people for the cities of Bam and Baravat and the surrounding villages. An official number of 31,500-31,828 was later established (Berberian 2014). In addition, between 17,500 and 50,000 people suffered injuries (Nadim et al. 2004; Berberian 2005; Garazhian and Papoli Yazdi 2008; Berberian 2014). Details about the death toll in various organizations and educational and health institutions in Bam are offered by Parsizadeh and Izadkhah (2005) and Berberian (2014). The direct economic losses were estimated at the value of USD 1.5 billion at that time (Berberian 2005).

The performance of the adobe residential buildings was disastrous during the Bam earthquake (Maheri et al. 2005). In Bam, the failure of non-engineered masonry with very heavy roofs and floor slabs caused a huge number of casualties (Maheri 2005). The 2003 Bam earthquake again highlighted the urgent need to improve the seismic performance of buildings in Iran. It was found that the application of wood, steel, and reinforced concrete ring beams and other connective elements impede the collapse of walls and roofs (Nadim et al. 2004; Maheri et al. 2005). These structural elements were implemented successfully and performed well during the $\mathrm{M}_{\mathrm{w}}$ 6.6 Fandoqa earthquake in 1998, which was similar in magnitude to the Bam earthquake and affected an area not far from Bam, in Kerman Province (Maheri et al. 2005). But the urgent need to improve the seismic performance of buildings in Iran emerged again after other earthquake disasters, such as the
Ahar-Varzeqan earthquake in 2012 and the ShonbehBushehr earthquake in 2013.

Seismic behavior of Bam's buildings highlighted the poor earthquake resistance of the welded connections for buildings' braced steel frames. This situation was observed for old and new buildings and both private and governmental buildings. Such widespread damage urged the improvement of the quality of welding work and to revise some of the traditional designs and construction procedures for welded connections used for buildings (Hosseinzadeh 2004).

Almost all of the essential buildings in Bam suffered structural and nonstructural damages; hospitals, medical centers, fire stations, police stations, various governmental buildings, mosques, and schools were either destroyed or suffered heavy damages. The earthquake severely affected their role as emergency facilities. This highlighted the lesson that vulnerability of essential buildings in Iran needs to be minimized (Nadim et al. 2004; Eshghi and Naserasadi 2005; Parsizadeh and Izadkhah 2005).

The 2003 Bam brought to attention the role of airport after an earthquake and its important contribution to the emergency response and relief. The Bam airport suffered only moderate damages to the main terminal, little damages to the runway, and nonstructural damages to the control tower (Nadim et al. 2004). As almost all hospitals and health care units in the Bam area were destroyed or suffered serious damages, tens of thousands injured people were airlifted to the hospitals in Kerman or to other major cities in Iran. Rescue and relief teams from Iran and around the world, with various equipment and materials, were flown also into Bam (Nadim et al. 2004; Eshghi and Ahari 2005; Abolghasemi et al. 2008).

The large amounts of debris and dust created by the collapse of adobe buildings in Bam caused many people to die of asphyxiation, and not necessarily because of major or fatal direct injuries. The absence of organized search and rescue missions in the first critical hours after the earthquake increased the death toll (Movahedi 2005; Tierney et al. 2005; Ibrion et al. 2015a). One of the Bam survivors recalled the experience of being trapped under debris and emphasized the discrepancy between what is usually perceived to be the experience of being trapped under debris and what is the real dramatic experience: "Many people think that being under debris meaning that the person is in close corner or stock in one space, but this is not true. I am thinking to create something and to show to authorities and organizations involved in rescue what does mean to be under debris" (Parsizadeh 2011, p. 107). The majority of people under the debris were saved by family members, relatives, neighbors, or other members of their community. This situation was identified with the occasion of previous 
earthquakes disasters such as the 1962 Buyin Zahra, 1978 Tabas, 1990 Rudbar (Ibrion et al. 2015a), and many other earthquake disasters in Iran (Berberian 2014). This underlines the lesson about the importance of "golden time" after an earthquake, the role of local communities in search and rescue, and the necessity to improve their earthquake risk awareness and earthquake disaster preparedness (Ibrion et al. 2015a).

The length of time trapped under rubble affects the development of crush syndrome or acute renal failure (ARF) (Hatamizadeh et al. 2006). Crush syndrome, ARF, or acute kidney injury (AKI) are different terms for a life threatening condition that is responsible for the death of many injured people after the earthquake. Acute renal failure can be prevented, or treated if people are extricated from under rubble rapidly and appropriate medical care treatment is provided in time. The role of nephrologists and the availability in short time of special dialysis units was also emphasized (Hatamizadeh et al. 2006; Fukagawa 2007). The Bam earthquake disaster offered one of the largest databases for analyzing people affected by ARF and contributed to proposing efficient strategies in dealing with ARF after disasters, in Iran and worldwide (Hatamizadeh et al. 2006).

After an earthquake, a sufficient amount of blood supplies needs to be available in very short time in order to treat the injured survivors. A lesson from the 2003 Bam concerned the disaster planning and emergency preparedness of the blood supplies for blood transfusions (Abolghasemi et al. 2008). The Bam disaster caused a large flow of blood donors from around Iran, but of the 108,985 total donated blood units, only 21,347 were distributed to the hospitals around the country. The hospitals in the Kerman region were overwhelmed in the first days after the earthquake, but they received only 1231 units of blood, a mere $1.3 \%$ of the total blood donated during the first four days after the earthquake. A high number of blood units were discarded because of blood safety issues (Abolghasemi et al. 2008). Poor national blood transfusion organization highlighted the lack of major disaster planning and emergency preparedness for the supply, coordination, and transfer of blood supplies, and necessity of efficient communication between hospitals and blood collection centers. It was identified that $76 \%$ of the blood units that reached the hospitals of Kerman Province were provided by neighboring provinces. For instance, Yazd Province with 923 blood units provided the highest number of blood units. Mobilizing first those provinces with rapid and easy access to the disaster area is vital in disaster planning for the blood supplies (Abolghasemi et al. 2008).

Within disaster management, a controversial matter is the risk of epidemics (Lopez-Carresi 2014). After the Bam earthquake, anthroponotic cutaneous leishmaniasis (ACL) or simply leishmaniases reached an epidemic stage. Massive destruction of houses, huge amounts of rubbles, dramatic alterations of the landscape, expansion of the city in the unhabituated areas, rapid changes in Bam demography, and poor sanitation conditions created favorable conditions for the propagation of sand-fly vector and transmission of ACL (Sharifi et al. 2011). The lesson concerned the disaster planning and preparedness in order to combat the outbreak of such diseases. The Iranian National Center for Disease Control prepared and implemented a national control program that targeted the improvement of diseases control strategies within the country. This program started in Bam and Kerman Province in 2006, three years after the earthquake (Sharifi et al. 2011). De Ville de Goyet (2007) highlighted also that in order to control the outbreak of various diseases after disasters, one of the first priorities has to be ensuring the function of sanitation services and the access to clean water. A rapid access to minimum standards of sanitation, toilets, and showers is a part of the biological needs that is often overlooked after an earthquake disaster. After the earthquake in Bam, health and the environmental conditions were affected by the shortage of drinking water, toilets, showers, waste collection and disposal, and more (Tierney et al. 2005). The lesson brought to attention that local materials and human resources of Bam needed to be involved in the repair and construction of sanitation services, such as toilets and showers (Pinera et al. 2005). The implementation of this lesson affected positively the well-being of survivors and their health. Bathrooms were shared, maintained, and cleaned among families who knew each other well. Moreover, the rapid access to water was required by beliefs and cultural traditions; various categories of Nages (uncleaned or untouchable) required purification and ablutions need to be performed before daily prayers (Ibrion et al. 2015b). After the 2013 Shonbeh-Bushehr earthquake, sanitation points and toilets were immediately installed in affected areas, but because they were not equipped with access to water, they cannot be used and survivors continued to use their own damaged places (IIEES 2013).

After the Bam earthquake, gender matters started to receive attention and various lessons emerged from the earthquake experiences of female survivors. Rescue and relief need to include female members in their teams and women and children requirements for privacy, clothing, and special toiletries items need to be carefully considered and planned for. The local capacities of women need to be included in relief and reconstruction efforts and their disaster experiences should be incorporated within disaster planning and earthquake awareness programs (Parsizadeh and Eskandari 2013). After the 2013 Shonbeh-Bushehr earthquake, gender matters were considered for the medical teams sent to the affected areas (IIEES Report 2013). 
In addition to a very high number of deaths of children (Sabri et al. 2006), the earthquake disaster of Bam left more than 6,500 children as orphans (Kunz 2009). Adding to the loss of families, relatives, friends, school colleagues, and neighbors, many of them suffered injuries and even life disabilities. In Bam, a special program that provided sport and playing facilities for children was implemented within the first months after the earthquake. The sports and play were identified as having positive effects on the psychosocial rehabilitation of children and youth, improving family relationships, building social networks, and contributing to the resilience of communities. It was remarked that the sport coaches had an important role for the positive results of the program. Moreover, coaches needed to be selected from the local population and given special support and training, as they also suffered from earthquake disaster trauma (Kunz 2009). However, the implementation and development of such programs require long-term financial resources and support from various organizations. Otherwise their contribution to the resilience of affected communities is not sustainable.

After the devastating Bam earthquake, the National Center for Earthquake Prediction (NCEP) was established by governmental decree at the International Institute of Earthquake Engineering and Seismology (IIEES). As part of the NCEP, a test site has been established in the Alborz mountain region for earthquake monitoring and possible future prediction/precursor detection purposes. The proximity of the test site to the capital of Iran-Tehran-with its high population density, low frequency but high magnitude earthquake occurrence, and active faults with historical earthquake events are the main criteria for this selection (Mokhtari 2010). An aftershock monitoring system (local dense seismic network) was established for a better understanding of the seismo-tectonic activity and to identify the main fault responsible for the earthquake occurrences (Tatar et al. 2004). These developments emphasized the necessity of preparedness and the implementation of an earthquake early warning system (EEWS), and a better understanding of precursory seismic activities in Iran. In addition, the requirement of having more seismic stations throughout Iran was recognized. An EEWS was implemented successfully in countries like Mexico and Japan. EEWS is also under advanced development in Turkey, Romania, the United States, Italy, and Taiwan and mainland China (Allen et al. 2009; Mokhtari 2010). The success of EEWS in Iran will be strengthened by a national long-term support, multidisciplinary approaches, use of different technologies, international collaboration, earthquake disaster risk awareness, public education and disaster preparedness, learning from earthquake disasters, and development of a culture of resilience and earthquake disaster risk reduction, among the communities and society (Mokhtari 2010; Ibrion et al. 2015c).

\section{Discussions}

Lessons from the Tabas 1978, Rudbar 1990, and Bam 2003 earthquake disasters were identified for various stages of earthquake disaster planning, rescue, medical emergency response, relief, short-term recovery, and short- and longterm reconstruction. These lessons still have a long way to go before being implemented towards earthquake disaster risk reduction in Iran. A mere identification of earthquake disasters lessons by academia, specialists, policymakers, various organizations and institutions, or even by survivors, does not mean that these lessons are becoming truly "Lessons Learned." Many of them were often forgotten or ignored, rather than being implemented and reached to the stage of "Lessons Learned." The next earthquake disasters are only a matter of time, if the lessons from earthquake disasters are still not "learned." A Bam survivor cautiously warned about this reality in Iran: "We think that disaster is in the news, disaster is not for us, disaster is for others. But, people do not realize that the next person might be them. It is just a matter of time" (Parsizadeh 2011, p. 109).

The repetition of earthquake disasters' lessons occurred both in time and various places of Iran. The three analyzed cases and other earthquake disasters in Iran have many lessons in common. For instance, one of these lessons concerned the urgent need to improve the seismic performance of buildings. After many deadly earthquake disasters in Iran, this essential lesson is still pending to be learned and the common saying "Buildings kill, not earthquakes!" is very much relevant. New lessons also emerged after each earthquake disaster, and the specificity of the place needs to be considered among others. For example, the Tabas and Bam earthquake disasters highlighted the specificity of earthquake disaster preparedness in arid and semi-arid areas of Iran and the correlation between fault lines, water sources, importance of Qanats, and resilience of the local communities (Nadim et al. 2004; Jackson 2006; Ibrion et al. 2014). Rudbar earthquake disasters brought to attention the specificity of earthquake disaster preparedness in mountainous areas of Iran. Risk posed by landslides and rock falls emerged as one of the essential lessons after the Rudbar earthquake. A comprehensive assessment of earthquake hazard needs to include also the hazard associated with earthquake-induced landslides (Rodriguez et al. 1999). This lesson was identified also after other earthquake disasters around the world. Two years prior to the Rudbar earthquake, immense damage was produced by earthquake-induced landslides after the Spitak 
earthquake in Armenia. In 2005, the Kashmir earthquake in Pakistan triggered massive landslides. The more than 60,000 landslides that occurred after the 2008 Wenchuan earthquake in Sichuan, China caused about one-third of the death toll (Huang and Fan 2013).

But a few lessons became "Lessons Learned" and contributed to earthquake disaster risk reduction in some places. A good example of such "Lesson Learned" with high impact on loss consequences is the 1998 Fandoqa earthquake in Iran. The good seismic performance of the reinforced buildings and structures significantly lowered the death toll and the building destruction (Maheri et al. 2005). The lesson of improving the seismic performance of the adobe building construction was implemented after this area had experienced two devastating earthquakes in 1981. The first earthquake-Golbaf earthquake-occurred on 11 June 1981 with a $\mathrm{M}_{\mathrm{w}}$ of 6.6 and caused 1400 fatalities and 3000 injuries. The second earthquake-Sirch earthquakeof $M_{w} 7.0$, occurred on 28 July 1981 and 1300 people were killed, 1000 were injured, and 25 villages were destroyed (Berberian 2005). The building reconstruction after the 1981 earthquake disasters resulted in reinforced buildings that did not suffer major damages and collapse after the 1998 Fandoqa earthquake. This was accomplished in simple and economical ways by improving the connections between the main load carriers and other structural elements of the buildings (Maheri et al. 2005).

Another lesson that is becoming a "Lesson Learned" is the enhancement of earthquake awareness and public education, especially among the young generations. This lesson started to become articulated after the Rudbar earthquake. Earthquake safety education was introduced in schools and earthquake drills were initiated in Tehran's high schools in 1996, extended to the whole country in 1999, and to secondary level education in 2000. From November 2003, earthquake drills in Iran were incorporated at all school levels (Parsizadeh et al. 2007). Students and teachers who attended earthquake drills applied the knowledge they gained in the 2002 Changureh-Avaj earthquake (Izadkhah and Hosseini 2010). During the 2013 Shonbeh-Bushehr earthquake, students and teachers also successfully applied the guidelines instructed during earthquake drills, rapidly and safely evacuated buildings, found safe places, and ensured the safety and security of children (IIEES 2013). But earthquake awareness-raising and public educations are long-term programs that require continuous updates and developments, financial resources, regulations, decision-making commitment, and national support. Internationally, after the 2011 Great East Japan Earthquake and Tsunami, the "Miracle of Kamaishi" became well-known. Almost 3000 elementary and junior high school students of Kamaishi in Iwate Prefecture survived the destructive tsunami waves through rapid evacuation to high and safe places. This outcome was the result of years of earthquake and tsunami awareness-raising, education, and drills performed at schools and a process of student empowerment (Ranghieri and Ishiwatari 2014).

In the years after the 1978 Tabas earthquake, the 1979 Islamic Revolution in Iran and the 1980-1988 Iran-Iraq war focused the attention and resources of communities and society on other more important and dramatic events. Lessons from the Tabas earthquake had to wait a long time to be learned and implemented towards earthquake disaster preparedness and disaster management. The 1990 Rudbar earthquake occurred two years after the end of the eight years' war with Iraq. The country was involved in post-war reconstruction and not prepared for such earthquake disaster. Direct economic losses were estimated at USD 7.2 billion, about $2.5 \%$ of the national GDP at that time (Berberian 2005).

The year of the Rudbar earthquake was also the first year of the initiative of the United Nations International Decade for Natural Disaster Reduction (IDNDR) 1990-1999. During the IDNDR around 266 earthquake disasters occurred around the world (Alcantara-Ayala, 2010). One year later, in 1991, a National Committee for Natural Disaster Reduction was established in Iran and a national mitigation plan named Iran Earthquake Hazard Mitigation Program (IEHMP) started. After nine years of program development, public earthquake awareness and engineering practice and knowledge were assessed to be at a reasonably high level. However, earthquake preparedness and earthquake mitigation were still at low levels (Ghafory-Ashtiany et al. 2000).

The 2003 Bam earthquake disaster brought together many old, forgotten, and ignored lessons from previous earthquake disasters and new lessons. The Bam earthquake created awareness for the need of interdisciplinary approaches in earthquake disaster preparedness in Iran. While interdisciplinary approaches are not easy to achieve, they are nonetheless essential strategies of earthquake disaster risk reduction and need to be applied within earthquake disaster management. Hiroyuki Aoyama, the Founding President of the Japan Association for Earthquake Engineering (JAEE), emphasized that one of the important "Lesson Learned" from the 1995 Kobe earthquake was the need for interdisciplinary work. JAAE was established in 2001 and interdisciplinary work became part of the organization's mission in working towards earthquake disaster preparedness (Irikura 2005). Researchers, experts, and various organizations and institutions need to cooperate towards earthquake disaster risk reduction.

After the Bam earthquake disaster the need for improved communication and accessible information about earthquake disasters in Iran became very clear (Parsizadeh 
2011). Communication about earthquake disasters is influenced by complex relationships among local communities, as well as regional, national, and international institutions and organizations prior to earthquake disasters (Atsumi and Okano 2004). The role of earthquake disaster diplomacy is also important and the contextual background and diplomatic relations between countries at the time of an earthquake need to be considered (Kelman 2012). After the earthquake disaster in Bam, Japan was very keen to share some of the "Lessons Learned" from the Kobe earthquake with institutions and nongovernmental organizations (NGOs) in Tehran, Kerman, and Bam. One of the shared lessons in Bam was that the international NGOs normally leave the affected area within a few months after the earthquake. Therefore, local NGOs and local organizations, together with governmental institutions and organizations, have a more important role to play in the relief and reconstruction processes than international NGOs (Fukagawa 2007). One lesson from the Kobe earthquake was that society's focus on and concern with earthquake disaster survivors do not last for a long time, but fade quickly. Atsumi and Okano (2004, p. 166) emphasized the importance of "collective remembering" and "collaborative remembering." For example, special exhibitions were organized in Japan with drawings of children from Bam, making Japanese people aware of other earthquake disasters in the world and their survivors. This lesson of keeping alive the Bam survivors' memory in the long term was initiated and started to be put in practice in Iran through the work of Parsizadeh (2011). It was also recommended that the disaster experience of survivors should be used in earthquake disaster mitigation strategies and disaster management planning and practices at local, regional, and national levels (Parsizadeh and Eskandari 2013; Ibrion et al. 2015a, b, c).

Earthquake risk perceptions are influenced by beliefs, values, history, space, time, and more. An omnipresent belief that influences the acceptance of earthquake disaster risk and also serves as a coping attitude is that an earthquake will not occur during the lifetime of the present generations. In the same time, lessons are trying to become "Lessons Learned" as part of the society's and communities' efforts to live with earthquake hazard and to try to mitigate the earthquake disaster risk. The role of uncertainty should be considered in the application of lessons in disaster risk reduction (Kasperson 2010). Japanese earthquake preparedness is well known around the world and its culture of earthquake disaster prevention, especially after the Kobe earthquake, greatly boosted the resilience of local communities. But the chain of disasters that occurred after the 2011 Great East Japan Earthquake and Tsunami, the nuclear power plant failure, and the resulting massive contamination were beyond the lessons and "Lessons
Learned" from previous disasters. This reinforces the Japanese saying "You can never be too prepared for earthquakes" (Fukagawa 2007, p. 803) and explains why the culture of continuous learning from past earthquake disasters and continuous improvement of the earthquake and tsunamis disaster preparedness is ingrained within Japanese society and local communities (Ranghieri and Ishiwatari 2014). A country situated in an area prone to high seismic activities needs to be prepared for the worst scenario, because it just might happen (Eisner 2013) and it is just a matter of time (Berberian 2014; Ibrion et al. 2015a). This Japanese model of culture of resilience and earthquake disaster risk reduction can be considered for adaptation to the Iran case.

\section{Conclusion}

Lessons from the Tabas, Rudbar, and Bam earthquake disasters present great potential for the improvement of earthquake disaster preparedness and reduction of toll of death, injuries, and massive destruction, and can make a sound contribution to the resilience of communities in Iran. But few lessons from the Tabas, Rudbar, and Bam earthquake disasters have been consistently applied in earthquake disaster management practices and contributed to the reduction of earthquake disaster risk in Iran. Many of the lessons from the large earthquake disasters of Tabas, Rudbar, and Bam did not become "Lessons Learned." To the contrary, these lessons were identified again in the dramatic context of other earthquake disasters in Iran. An amalgam of old and new lessons from earthquake disasters is being repeated in different places in Iran.

Lessons and even "Lessons Learned" from the Tabas, Rudbar, and Bam earthquake disasters require a sustainable long-term framework - an earthquake culture in Iran: a culture of knowing to live with earthquake hazard, a culture of earthquake awareness and earthquake disaster preparedness, and a culture of resilience among communities and society. Policymakers, laws and regulations system, decision-making processes, various organizations and institutions, academia, specialists, and local communities need to unite their efforts towards such culture. The Japanese culture of learning from earthquake disasters can also serve as a model for Iran and eventually accountable actions for the earthquake risk reduction for all present generations, and those yet to come, become more than just articulated.

Acknowledgments The first author greatly acknowledges the financial support from the International Centre for Geohazards (ICG)/ Norwegian Geotechnical Institute (NGI), Oslo, Norway for the research and field trips to Iran. The first author would like to thank Mr. Farokh Parsizadeh, Prof. Ghafouri-Ashtiany, Dr. Manoucher 
Qoreshi, Dr. Morteza Talebian, Dr. Sasan Eshghi, Mr. Hirad Nadim, Dr. Amir Nejad, Mrs. Maryam Pakdaman Naeini, and Prof. Haakon Lein for their kind, generous support, useful comments, and fruitful discussions. The authors would like to thank the editors and three anonymous reviewers for their valuable constructive comments and recommendations.

Open Access This article is distributed under the terms of the Creative Commons Attribution 4.0 International License (http://creative commons.org/licenses/by/4.0/), which permits unrestricted use, distribution, and reproduction in any medium, provided you give appropriate credit to the original author(s) and the source, provide a link to the Creative Commons license, and indicate if changes were made.

\section{References}

Abolghasemi, H., M.H. Radfar, M. Tabatabaee, N.S. HosseiniDivkolayee, and F.M. Burkle. 2008. Revisiting blood transfusion preparedness: Experience from the Bam earthquake response. Prehospital Disaster Medicine 23(5): 391-394.

Alcantara-Ayala, I. 2010. Geomorphology and disaster prevention. In Geomorphological hazards and disaster prevention, ed. I. Alcantara-Ayala, and A. Goudie, 269-278. New York: Cambridge University Press.

Alexander, D. 2012a. Disasters: Lessons learned? Journal of Geography and Natural Disasters 2(1): 1-2.

Alexander, D. 2012b. What can we do about earthquakes? Towards a systematic approach to seismic risk mitigation. Bulletin of the New Zeeland Society for Earthquake Engineering 45: 1-16.

Allen, M.R., P. Gasparini, O. Kamigaichi, and M. Bose. 2009. The status of earthquake early warning around the world: An introductory overview. Seismological Research Letters 80(5): 682-693.

Ambraseys, N.N., and C.P. Melville. 1982. A history of Persian earthquakes. New York: Cambridge University Press.

Astaneh-Asl, A. 1994. Lessons of the 1990 Manjil-Iran earthquake. 10th European Conference on Earthquake Engineering, Vienna, 28 August-2 September 1994, 6997-7000. Rotterdam: Balkema.

Astaneh, A., and M. Ghafory-Ashtiany. 1990. The Manjil, Iran, earthquake of June 21, 1990. Earthquake Engineering Research Institute Newsletter 24(12): 5-12.

Atsumi, T., and K. Okano. 2004. Disaster relief from Kobe and its significance in the Bam, Iran earthquake of December 26, 2003. Bulletin Earthquake Research Institute University of Tokyo 79: 163-169.

Beck, U. 2008. World at risk: The new task of critical theory. Development and Society 37(1): 1-21.

Berberian, M. 1979. Tabas-e-Golshan (Iran) catastrophic earthquake of 16 September 1978; A preliminary field report. Disasters 2(4): 207-219.

Berberian, M. 2005. The 2003 Bam urban earthquake: A predictable seismotectonic pattern along the western margin of the rigid Lut Block, southeast Iran. Earthquake Spectra 1(S1): S35-S99.

Berberian, M. 2014. Earthquakes and coseismic surface faulting on the Iranian Plateau, A historical, social and physical approach. Amsterdam: Elsevier.

Berberian, M., and R. Walker. 2010. The Rudbar $\mathrm{M}_{\mathrm{w}} 7.3$ earthquake of 1990 June 20, seismotectonics, coseismic and geomorphic displacements, and historic earthquakes of the western "High-Alborz" Iran. Geophysical Journal International 183(3): 1577-1602.

Berberian, M., M. Qorashi, J.A. Jackson, K. Priestley, and T. Wallace. 1992. The Rudbar-Tarom earthquake of 20 June 1990 in NW Persia: Preliminary field and seismological observations, and its tectonic significance. Bulletin of the Seismological Society of America 82(4): 1726-1755.
Bilham, R. 2009. The seismic future of cities. Bulletin of Earthquake Engineering 7: 839-887.

De Ville de Goyet, C. 2007. Health lessons learned from the recent earthquakes and tsunami in Asia. Prehospital and Disaster Medicine 22(1): 15-21.

Eisner, R. 2013. Preparing for the worst case...because it just might happen. Earthquake Spectra 29(S1): S339-S340.

Eshghi, S., and M.N. Ahari. 2005. Performance of transportation systems in the 2003 Bam, Iran, earthquake. Earthquake Spectra 21(S1): S455-S468.

Eshghi, S., and K. Naserasadi. 2005. Performance of essential buildings in the 2003 Bam, Iran, earthquake. Earthquake Spectra 21(S1): S375-S393.

Ettelaat Archives. 1978. 20 September 1978, No 15716. Published by the Ettelaat Organization, Tehran, Iran. Retrieved from the 1978 Archival Documents at the Library, Museum and Document Center of the Iran Parliament (In Farsi).

Fukagawa, M. 2007. Nephrology in earthquakes: Sharing experiences and information. Clinical Journal of the American Society of Nephrology 2: 803-808.

Garazhian, O., and L. Papoli Yazdi. 2008. Mortuary practices in Bam after the earthquake. An ethnoarchaeological study. Journal of Social Archaeology 8(1): 94-112.

Ghafory-Ashtiany, M., M-H. Jafari, and M. Tehranizadeh. 2000. Earthquake hazard mitigation achievement in Iran. 12th World Conference on Earthquake Engineering, Auckland, New Zealand, 30 January-4 February 2000, Paper 2380.

Glantz, H.M., and I. Kelman. 2013. Thoughts on dealing with climate change...As if the future matters. International Journal of Disaster Risk Science 4(1): 1-8.

Hatamizadeh, P., I. Najafi, R. Vanholder, F. Rashid-Farokhi, H. Sanadgol, S. Seyrafian, A. Mooraki, S. Atabak, et al. 2006. Epidemiologic aspects of the Bam earthquake in Iran: The nephrologic perspective. American Journal of Kidney Diseases 47(3): 428-438.

Hosseinzadeh, N.A. 2004. Lessons learned from steel braced buildings damaged by the Bam earthquake of 26 December 2003. Journal of Seismology and Earthquake Engineering 5(4): 111-121.

Huang, R., and X. Fan. 2013. The landslide story. Nature Geoscience 6: 325-326.

Ibrion, M., H. Lein, M. Mokhtari, and F. Nadim. 2014. At the crossroad of nature and culture in Iran: The landscapes of risk and resilience of seismic space. International Proceedings of Economics Development and Research 71: 38-44.

Ibrion, M., M. Mokhtari, F. Parsizadeh, and F. Nadim. 2015a. Timescape of the earthquake disasters in Iran: The intricacies of earthquake time and earthquake disaster risk reduction. Geografiska Annaler: Series A, Physical Geography 97(1): 197-216.

Ibrion, M., F. Parsizadeh, M. Pakdaman Naeini, M. Mokhtari, and F. Nadim. 2015b. Handling of dead people after two large earthquake disasters in Iran: Tabas 1978 and Bam 2003Survivors' perspectives, beliefs, funerary rituals, resilience and risk. International Journal of Disaster Risk Reduction 11: 60-77.

Ibrion, M., M. Mokhtari, F. Parsizadeh, H. Lein, and F. Nadim. 2015c. Towards a culture of resilience and earthquake disaster risk reduction in Iran- "Lessons-Learned" from earthquake disasters. Proceedings of the 7th International Conference on Seismology and Earthquake Engineering, 18-21 May 2015, Tehran, Iran.

ICG (International Centre for Geohazards/Norwegian Geotechnical Institute). 2004. Bam earthquake of 26 December 2003, ICG Reconnaissance Mission, ICG report 2004-99-1, 16 April 2004 / NGI Report 20041057-1, Revision 1-01 June 2004. Oslo.

IIEES (International Institute of Earthquake Engineering and Seismology). 1990. The Manjil-Rudbar earthquake of June 20, 1990 Iran. Report No. 70-90-1, May 1990. Tehran (in Farsi). 
IIEES (International Institute of Earthquake Engineering and Seismology). 2013. The $M_{w} 6.4$ Shonbeh (Bushehr) earthquake on 9 April 2013 at 16.22 local time, in the Borazjan region. Tehran: IIEES (in Farsi).

Irikura, K. 2005. Importance of hazard risk assessment. Presentation at the Thematic Session 3-5, at World Conference on Disaster Reduction, 18-22 January 2005, Kobe. http://www.unisdr.org/ 2005/wcdr/thematic-sessions/presentations/session3-5/jaee-mririkura2.pdf. Accessed 15 Aug 2013.

Izadkhah, Y.O., and K.A. Hosseini. 2010. An evaluation of disaster preparedness in four major earthquakes in Iran. Journal of Seismology and Earthquake Engineering 12(1-2): 61-75.

Jackson, J. 2006. Fatal attraction: Living with earthquakes, the growth of villages into megacities, and earthquake vulnerability in the modern world. Philosophical Transactions of the Royal Society of London 364(1845): 1911-1925.

Jaeger, C. 2010. Risk, rationality, and resilience. International Journal of Disaster Risk Science 1(1): 10-16.

Kasperson, R.E. 2010. Science and disaster reduction. International Journal of Disaster Risk Science 1(1): 3-9.

Kelman, I. 2012. Disaster diplomacy: How disasters affect peace and conflict. New York: Routledge.

Krausmann, E., and F. Mushtaq. 2006. A methodology for learning lessons. Experiences at the European level. In Measuring vulnerability to natural hazards, ed. J. Birkmann, 415-431. New Delhi: United Nations University Press.

Kunz, V. 2009. Sport as a post-disaster psychosocial intervention in Bam, Iran. Sport in Society 12(9): 1147-1157.

Lacasse, S., and F. Nadim. 2011. Learning to live with geohazards: From research to practice. In Geo-risk 2011: Risk assessment and management, Proceedings of GeoRisk 2011, 26-28 June, Atlanta, Georgia, ed. C.H. Juang, K.K. Phoon, J.A. Puppala, A.R Green, and A.G. Fenton, 64-116. American Society of Civil Engineers.

Lacasse, S., F. Nadim, and K. Høeg. 2012. Risk assessment and mitigation in geo-practice. In Geotechnical engineering state of the art and practice: Keynote lectures from GeoCongress 2012, March 25-29, Oakland, California, ed. K. Rollins, and D. Zekkos, 729-764. American Society of Civil Engineers.

Lacasse, S., F. Nadim, K. Høeg, and O. Gregersen. 2004. Risk assessment in geotechnical engineering: The importance of engineering judgement. In Advances in geotechnical engineering, the Skempton Conference Proceedings, vol. 2, 856-867. London: Thomas Telford Publishing.

Leroy, S.A.G., S. Warny, H. Lahijani, E.L. Piovano, D. Fanetti, and A.R. Berger. 2010. The role of geosciences in the mitigation of natural disasters: Five case studies. In Geophysical hazards, minimizing risk, maximizing awareness, ed. T. Beer, 115-147. Berlin and Heidelberg: Springer.

Lopez-Carresi, A. 2014. Common myths and misconceptions in disaster management. In Disaster management, international lessons in risk reduction, response and recovery, ed. A. LopezCarresi, M. Fordham, B. Wisner, I. Kelman, JC Gaillard, 142-159. New York: Routledge.

Maheri, R.M. 2005. Performance of buildings roofs in the 2003 Bam, Iran, Earthquake. Earthquake Spectra 21(S1): S411-S424.

Maheri, R.M., F. Naeim, and M. Mehrain. 2005. Performance of adobe residential buildings in the 2003 Bam, Iran, earthquake. Earthquake Spectra 21(S1): S337-S344.

Mokhtari, M. 2010. Earthquake prediction activities and Damavand earthquake precursor test site in Iran. Natural Hazards 52(2): 351-368.

Movahedi, H. 2005. Search, rescue, and care of the injured following the 2003 Bam, Iran, earthquake. Earthquake Spectra 21(S1): S475S485.

Nadim, F., M. Moghtaderi-Zadeh, C. Lindholm, A. Andresen, S. Remseth, M.J. Bolourchi, M. Mokhtari, and E. Tvedt. 2004. The
Bam earthquake of 26 December 2003. Bulletin of Earthquake Engineering 2: 119-153.

Ozerdem, A., and S. Barakat. 2000. After the Marmara earthquake: Lessons for avoiding short cuts to disasters. Third World Quarterly 21(3): 425-439.

Parsizadeh, F. 2011. Survey on dissemination of information on earthquakes, a case study on December 26 of 2003, Bam earthquake. Tehran: International Institute of Earthquake Engineering and Seismology (in Farsi).

Parsizadeh, F., and O.Y. Izadkhah. 2005. Impact of the 2003 Bam, Iran, earthquake on the personnel and functioning of local government organizations. Earthquake Spectra 21(S1): S29-S34.

Parsizadeh, F., and M. Eskandari. 2013. Capabilities and needs of women in disaster-Case study of Bam earthquake, 26 December 2003. Research Bulletin of IIEES 16(1): 59-72.

Parsizadeh, F., M. Ghafory-Ashtiany, V. Heshmati, and A-E. Seif. 2007. Iran's school earthquake safety initiative. Regional Development Dialogue-Earthquake safety of schoolchildren 28(2): 33-46. Nagoya: United Nations Centre for Regional Development.

Pinera, J-F., A.R. Reed, and C. Njiru. 2005. Restoring sanitation services after an earthquake: Field experience in Bam, Iran. Disasters 29(3): 222-236.

Ranghieri, F., and M. Ishiwatari. 2014. Learning from megadisasters, lessons from the Great East Japan Earthquake. Washington, DC: The World Bank.

Rodriguez, C.E., J.J. Bommer, and R.J. Chandler. 1999. Earthquakeinduced landslides: 1980-1997. Soil Dynamics and Earthquake Engineering 18: 325-346.

Sabri, C.R., P. Miller, and R. Dierkx. 2006. Rebuilding a sustainable image in a cultural landscape. Environmental Sciences 12: 49-58.

Shahrivar, H., and H. Nadim. 2005. The morphology, setting and processes of Rudbar and Fatalak landslides triggered by 1990 Manjil-Rudbar earthquake in Iran. Master thesis in geosciences, University of Oslo, Norway.

Sharifi, I., N. Nakhaei, M.R. Aflatoonian, M. Hakimi Parizi, A.R. Fekri, H. Safizadeh, M.R. Shirzadi, M.M. Gooya, et al. 2011. Cutaneous leishmaniasis in Bam: A comparative evaluation of pre- and post-earthquake years (1999-2008). Iranian Journal of Public Health 40(2): 49-56.

Simpson, E., and S. Corbridge. 2006. The geography of things that may become memories: The 2001 earthquake in Kachchh-Gujarat and the politics of rehabilitation in the prememorial era. Annals of the Association of American Geographers 96(3): 566-585.

Tatar, T., D. Hatzfeld, A.S. Moradi, A. Paul, A.M. Farahbod, and M. Mokhtari. 2004. Aftershocks study of the 26 December 2003 Bam earthquake. Journal of Seismology and Earthquake Engineering 5(4): 23-31.

Thywissen, K. 2006. Core terminology of disaster reduction: A comparative glossary. In Measuring vulnerability to natural hazards, ed. J. Birkmann, 448-496. New Delhi: United Nations University Press.

Tierney, K., B. Khazai, T.Tobin, and F. Krimgold. 2005. Social and public policy issues following the 2003 Bam, Iran, earthquake. Earthquake Spectra 21(S1): S513-534.

Yasamy, M.T., M. Farajpour, S.S. Gudarzi, S.A. Bagheri Yazdi, A. Bahramnezhad, Y. Mottaghipor, A. Zamyad, M. Aminesmaeeli, et al. 2006. Disaster mental health care in Iran-responses based on needs. In Advances in disaster mental health and psychological support, ed. O.J. Prewitt Diaz, S.R. Murthy, and R. Lakshminarayana, 61-68. New Delhi: Voluntary Health Association of India Press.

Zhang, L., X. Liu, Y. Li, Y. Liu, Z. Liu, J. Lin, J. Shen, X. Tang, Y. Zhang, and W. Liang. 2012. Emergency medical rescue efforts after a major earthquake: Lessons from the 2008 Wenchuan earthquake. Lancet 379(9818): 853-861. 